\title{
Human antibody response to lipopolysaccharides from Neisseria gonorhoeae
}

\author{
M. E. WARD AND A. A. GLYNN \\ From the Department of Bacteriology, St Mary's Hospital Medical School, London
}

SYNOPSIS Red cells coated with lipopolysaccharides from three different strains of Neisseria gonorhoeae have been used as antigens in a haemagglutination test for gonococcal antibodies. For each strain the geometric mean titre in sera from 50 male and 25 female patients was significantly higher than that in 50 normal controls.

The most useful smooth strain, G1, picked out $84 \%$ of females and $46 \%$ of males from a group of patients known to have gonorrhoea, but only gave $2 \%$ positives among controls. The rough strain, G2, gave $10 \%$ positives in controls and $31 \%$ in patients. The results suggest that the method is worth developing further as a diagnostic test and that strain differences are important. False positives were probably due to cross-reacting antibodies.

A good serological test is urgently needed for the diagnosis of gonorrhoea, particularly in women where cultural methods are unsatisfactory. Such a test would also be valuable in epidemiological work where technical and psychological difficulties make widespread cultural investigations impracticable. The possibility of developing a serological technique has seemed more likely since the demonstration of an early antibody response to experimental infection (Cohen, Kellogg, and Norins, 1969). It must, of course, be remembered that in these experiments the inoculum, and hence the antigenic stimulus, was very large, certainly more than would be found in the early days of a new natural infection.

The traditional gonococcal complement-fixation test (Price, 1930) is used in the diagnosis of chronic rather than acute cases and even then is not regarded as very reliable. In recent years several new tests have been described though none are yet in routine use.

Cohen and his coworkers (Cohen, 1967; Cohen et al, 1969) detected antibodies to gonococci in patients with gonorrhoea by means of a fluorescent technique. They also found antibodies in some normal subjects but there were differences in the specificity, titre, and class of immunoglobulins involved.

Reising and Kellogg (1965) used a protein extracted with phenol as the antigen in a microprecipitin test. Positive results were obtained in $62 \%$ of male and female patients with gonorrhoea confirmed by culture and in no normal controls.

Received for publication 29 April 1971.
An antigen, 'A', of unknown chemical nature has been prepared by fractionation of gonococcal protoplasm on DEAE-Sephadex (Schmale, Danielson, Smith, Lee, and Peacock, 1969). In a complement-fixation test the A antigen reacted with $72 \%$ of sera from infected females, $20 \%$ from infected males, and with no normal sera (Reising, Schmale, Danielson, and Thayer, 1969).

Another protoplasmic antigen, B, has also been described (Lee and Schmale, 1970). In a slide flocculation test it reacted with sera from $86 \%$ of female and $68 \%$ of male patients, and with $12 \%$ of normal controls.

Both A and B antigens are described as protoplasmic in origin because they were obtained by differential centrifugation of gonococci disrupted in a Ribi cell press (Martin, Peacock, Reising, Kellogg, Ribi, and Thayer, 1969). However, the possibilities that they may contain cell wall precursors or lightweight products of cell wall disintegration have not been excluded.

A very sensitive microprecipitin test described by Chacko and Nair (1969) detected antibody in $60 \%$ of patients with a urethral discharge of less than three days' duration. The antigen was extracted with ethanol from the allantoic fluid of hens' eggs which had been infected with gonococci, but although the authors suggest it was a lipopolysaccharide, it must have been degraded as it was unable to produce a Schwartzman reaction.

One factor which has slowed the development of serological tests is the notorious variability of 
Neisseria gonorrhoeae and the difficulty in preparing well characterized stable and reproducible specific antigens. With strains in which the number of subcultures has been kept to a minimum, considerable heterogeneity is shown by bactericidal tests with human complement and rabbit immune antibodies. The major antigens concerned in the bactericidal reaction are lipopolysaccharides. These antigens could also be used to sensitize red cells for a haemagglutination test, and it was noticed that they then showed more cross reactions with a range of specific antisera than they did in the bactericidal reaction (Glynn and Ward, 1970).

We report here the results of a preliminary investigation into the diagnostic possibilities of the haemagglutination reaction. The antigens used were lipopolysaccharides from three serologically different strains of $N$. gonorrhoeae. These particular three were selected because from the bactericidal results G1 was found to be common among strains of $N$. gonnorhoeae, and G36 to be relatively rare. G2 is thought to be a partially degraded lipopolysaccharide from a rough strain.

\section{Materials and Methods}

SERA

Consecutive sera were obtained from 50 male and 25 female patients attending the Venereal Diseases Department at St Mary's Hospital, with positive smears for Neisseria and clinical symptoms of gonorrhoea. Control normal sera were obtained from 26 male and 24 female donors submitting blood for routine grouping. After triple absorption with $10 \% \mathrm{v} / \mathrm{v}$ packed sheep red cells for 18 to 20 hours at $4^{\circ} \mathrm{C}$ to remove Forssman antibody, the sera at 1:2 dilution no longer agglutinated sheep red cells.

GONOCOCCAL LIPOPOLYSACCHARIDES

Extracts were prepared from gonococci by a modifi- cation of Westphal's phenol-water method (Maeland, 1968). Identical preparations had previously been shown to be lipopolysaccharide in nature (Glynn and Ward, 1970).

The strains of gonococci used were of different serogroups when tested in the bactericidal reaction. Strains G1 and G36 were isolated from patients attending the Venereal Diseases Clinic at St Mary's Hospital. Strain G2 was from the National Collection of Type Cultures, Colindale (NCTC 8375). The strains, together with the methods of culture and subculture, have been previously described (Glynn and Ward, 1970; Ward and Watt, 1971).

\section{HAEMAGGLUTINATION REACTION}

In order to avoid the problem of variable sensitization between preparations made at different times, large batches of red cells were preserved by treatment with glutaraldehyde (Bing, Weyand, and Stavitsky, 1967). After treatment with alkali (Davies, Crumpton, Macpherson, and Hutchison, 1958) the concentration of lipopolysaccharides was made up to $12.5 \mu \mathrm{g} / \mathrm{ml}$ in Dulbecco's phosphate-buffered saline, $p \mathrm{H} 7 \cdot 3$, and incubated with an equal volume of a $2.5 \%$ suspension of glutaraldehyde-fixed red cells for one hour at $37^{\circ} \mathrm{C}$. The sensitized cells were washed three times in Dulbecco's solution, and preserved as a $2 \% \mathrm{v} / \mathrm{v}$ suspension with $1: 10,000$ merthiolate. Sheep red cells treated in this way retained the ame serological specificity and degree of sensitization after storage for at least six months at $4^{\circ} \mathrm{C}$.

The haemagglutination was carried out in Perspex trays by adding $0 \cdot 1 \mathrm{ml}$ volumes of the appropriate $0.5 \mathrm{v} / \mathrm{v}$ sensitized red cell suspension to equal volumes of serial two-fold dilutions of the sera. The diluent was Dulbecco's solution containing $1 \%$ normal rabbit serum, which had been previously absorbed with sheep red cells. After incubation for one hour at $37^{\circ} \mathrm{C}$ and overnight at $4^{\circ} \mathrm{C}$ the results were read the following morning. Negative controls routinely included sensitized red cells in diluent

\begin{tabular}{|c|c|c|c|c|c|c|c|c|c|}
\hline \multirow[t]{3}{*}{ Serum } & \multicolumn{9}{|c|}{ Lipopolysaccharide from N. gonorrhoeae Strains } \\
\hline & \multicolumn{3}{|l|}{$G 1$} & \multicolumn{3}{|l|}{$G 2$} & \multicolumn{3}{|l|}{$G 36$} \\
\hline & $\mathrm{GMT}^{\mathbf{1}}$ & $\mathbf{S D}^{2}$ & ${ }^{3} \mathrm{CV}$ & GMT & SD & CV & GMT & SD & $\mathbf{C V}$ \\
\hline $\begin{array}{l}\text { Male patients } \\
\text { Female patients } \\
\text { Controls }\end{array}$ & $\begin{array}{l}5 \cdot 24 \\
5 \cdot 96 \\
2 \cdot 70\end{array}$ & $\begin{array}{l}1 \cdot 45 \\
1 \cdot 46 \\
2 \cdot 1\end{array}$ & $\begin{array}{l}28 \\
24 \\
76\end{array}$ & $\begin{array}{l}6 \cdot 72 \\
6 \cdot 91 \\
4 \cdot 89\end{array}$ & $\begin{array}{l}1 \cdot 16 \\
0 \cdot 81 \\
1 \cdot 65\end{array}$ & $\begin{array}{c}17 \\
12 \\
33\end{array}$ & $\begin{array}{l}6 \cdot 64 \\
6 \cdot 84 \\
3 \cdot 86\end{array}$ & $\begin{array}{l}1 \cdot 03 \\
0 \cdot 98 \\
2 \cdot 1\end{array}$ & $\begin{array}{l}15 \\
14 \\
53\end{array}$ \\
\hline
\end{tabular}

Table I Mean and degree of variation of haemagglutination titres of patients and control sera

${ }^{1}$ GMT $=$ geometric mean titre in $\log 2$ units

${ }^{2} \mathrm{SD}=$ standard deviation in $\log 2$ units

${ }^{3} \mathrm{CV}=$ coefficient of variation $(\%)$

Comparison by $t$ test showed that for all strains the patients' GMT was significantly greater than that of the controls (P<0.001).

Female patients had a significantly higher titre than male against strain $G 1(P<0 \cdot 025)$, but not against strain $G 2(P>0.25)$ or strain $G 36(P>0.2)$ Comparison of sample variances by the $F$ test showed significantly greater dispersion of control compared with patient titres. 
alone and unsensitized red cells in dilutions of the sera.

\section{Results}

The distribution of haemagglutination titres of patients and control sera tested against red cells sensitized with lipopolysaccharides from the three strains of gonococci used is given in the Figure. For all three strains the geometric mean titre of the patients' sera was significantly greater than that of the controls (Table I). Female patients had slightly higher titres than males, the difference being statistically significant for tests against G1 but not G2 or G36 lipopolysaccharides. The women had all been infected for at least a month but further subdivision by length of infection was not possible. In the men there were no significant differences in titre according to the duration or number of infections. There were no significant differences between male and female control sera.

If the upper limit of normal is taken as four times the geometric mean titre of the control sera for each antigen, then there was a clear difference between the percentage positive in patients and controls (Table II). There were few positive controls with the smooth strains G1 and G36, markedly more with the rough strain G2. There were nearly twice as many positives among female as compared with male patients with strain $\mathrm{G} 1$, but no difference with strain G36. Strain G2 gave fewer in both sexes.

\begin{tabular}{|c|c|c|c|c|}
\hline \multicolumn{2}{|l|}{ Serum } & \multicolumn{3}{|c|}{ Strain of Gonococcus } \\
\hline Source & No. & $G 1$ & $G 2$ & G36 \\
\hline $\begin{array}{l}\text { Normal M } \\
\text { Normal F } \\
\text { Normal total }\end{array}$ & $\begin{array}{l}24 \\
26 \\
50\end{array}$ & $\begin{array}{l}0 \\
4 \\
2\end{array}$ & $\begin{array}{r}4 \\
16 \\
10\end{array}$ & $\begin{array}{l}4 \\
4 \\
4\end{array}$ \\
\hline $\begin{array}{l}\text { Gc M } \\
\text { Gc F } \\
\text { Gc total }\end{array}$ & $\begin{array}{l}50 \\
25 \\
75\end{array}$ & $\begin{array}{l}46 \\
84 \\
59\end{array}$ & $\begin{array}{l}33 \\
27 \\
31\end{array}$ & $\begin{array}{l}60 \\
60 \\
60\end{array}$ \\
\hline
\end{tabular}

Table II Percentage sera with antigonococcal lipopolysaccharide titres greater than $4 \times$ normal geometric mean titre

The variances of the sample titres were calculated and compared using an $\mathrm{F}$ test. The dispersion of titres of normal sera was significantly greater than

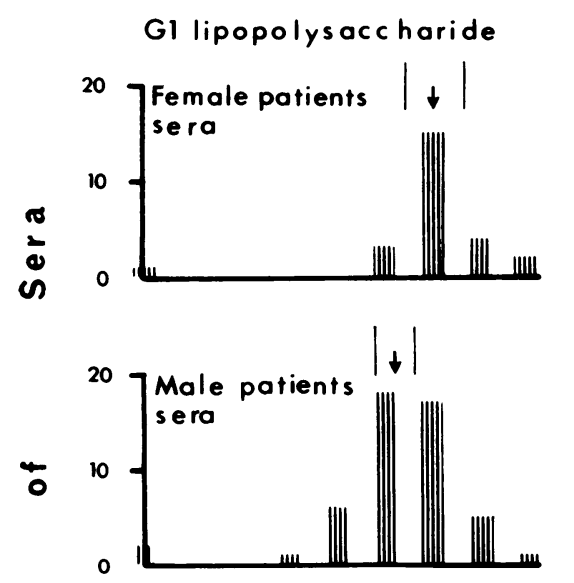

G2 lipopolysaccharide
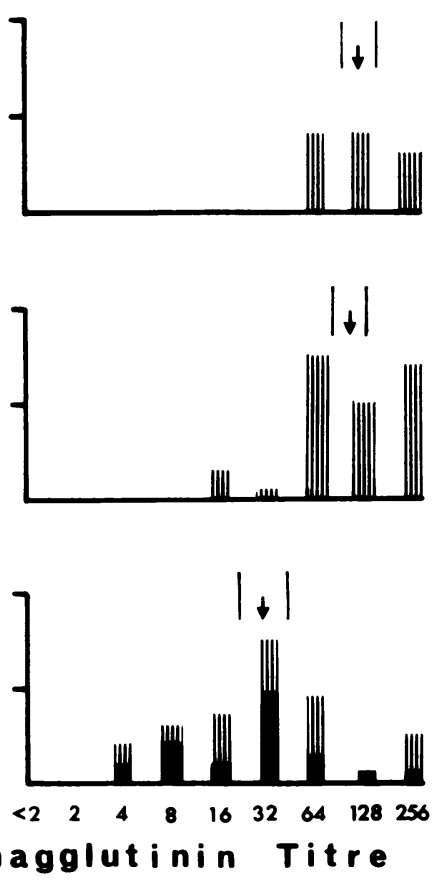

G36 lipopolysaccharide
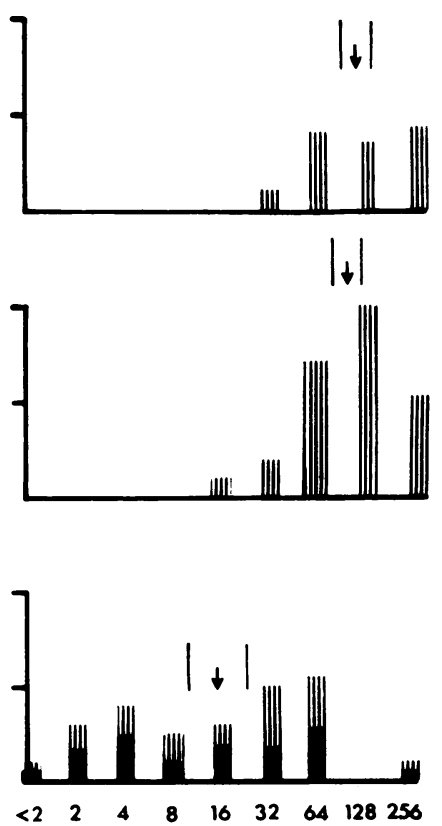

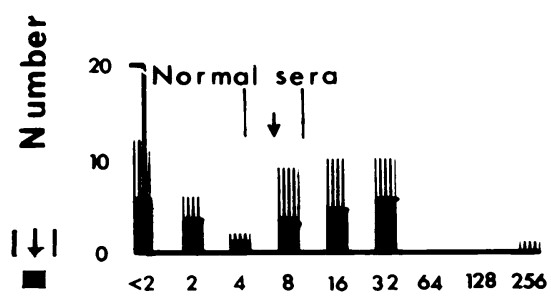

Haemaglutinin Titre

Fig. Haemagglutination titres against gonococcal lipopolysaccharides in patients with gonorrhoea and in normal controls $|\downarrow|$ geometric mean titre and $95 \%$ confidence limits $\square$ male control sera $\square$ female control sera 
that of the patients' sera. There was no significant difference in variance between male and female sera in either patient or control groups. The variability among control sera was least with the G2 antigen.

Because the degree of red cell sensitization differed for each of the three lipopolysaccharide preparations, it is not possible to make a strict comparison of serum titres against the different antigens. However, examination of the overall results suggests that the cells treated with G1 lipopolysaccharide were about half as sensitive as those treated with G2 or G36.

\section{Discussion}

This preliminary study of the distribution of antibody to three gonococcal lipopolysaccharides shows a clear distinction between normal and infected populations. In any individual serum there was a $2-4 \%$ chance of a false positive result. The chance of a false negative result varied but with the best strain was $16 \%$ for female patients, who are the group in whom a serological test is most needed. Not surprisingly the results using a rough strain of gonococcus showed much less specificity. Moreover, there is no certainty that G1 and G36 had not lost some antigenic specificity; other, perhaps fresher strains might do better. False-positive reactions were presumably due to cross-reacting antibodies originally raised against non-pathogenic Neisseria and other organisms (Glynn and Ward, 1970). They could probably be reduced by suitable adsorption but this would insert an extra step into the test. Substitution of human group $O$ cells for sheep red cells would enable the present absorption step to be eliminated. However, even with the results as they stand the figures using strain G1 are encouraging although much further testing is required.

The existence of cross-reacting natural antibodies would explain the greater dispersion of titres in the control sera when compared with the patients. It might be that the increased titres in patients' sera therefore represented a secondary response.

Patients usually responded to all three antigens, though not to the same degree. Whether some unsuspected common antigenic determinant was involved or whether most patients had been exposed to a large variety of gonococci is not known. It is likely that the alkali treatment of lipopolysaccharides needed to attach them to red cells reduced their specificity somewhat (Ciznar and Shands, 1970).

It was surprising that for G36 the mean titre in female patients was the same as in males and that for all strains the frequency or duration of attacks also had no detectable effect on the antibody level. The situation is reminiscent of the antibody response to a Haemophilus influenzae antigen found in patients with chronic bronchitis (Glynn, 1959). Here too antibody levels were unaffected by acute attacks or duration of illness except that they tended to be higher after 10 to 20 years. In both gonorrhoea and chronic bronchitis there are infections of a mucous membrane with little penetration by bacteria and a relatively small antigenic mass.

We thank the World Health Organization for a grant supporting this work, and Drs F. J. G. Jefferiss and R. R. Wilcox for providing the patients' sera.

\section{References}

Bing, D. H., Weyand, J. G. M., and Stavitsky, A. B. (1967). Hemagglutination with aldehyde-fixed erythrocytes for assay of antigens and antibodies. Proc. Soc. exp. Biol. (N.Y.), 124, 1166-1170.

Chacko, C. W., and Nair, G. M. (1969). Sero-diagnosis of gonorrhoea with a microprecipitin test using a lipopolysaccharide antigen from N. gonorrhoeae. Brit. J. vener. Dis., 45, 33-39.

Ciznar, I., and Shands, J. W. Jr. (1970). Effect of alkali on the immunological reactivity of lipopolysaccharide from Salmonella typhimurium. Infect., Immun., 2, 549-555.

Cohen, I. R. (1967). Natural and immune human antibodies reactive with antigens of virulent Neisseria gonorrhoeae: immunoglobulins G, M and A. J. Bact., 94, 141-148.

Cohen, I. R., Kellogg, D. S. Jr., and Norins, L. C. (1969). Serum antibody response in experimental human gonorrhoea. Immunoglobulins G, A and M. Brit. J. vener. Dis., 45, 325-327.

Davies, D. A. L., Crumpton, M. J., Macpherson, I. A., and Hutch ison, A. M. (1958). The adsorption of bacterial polysaccharides by erythrocytes. Immunology, 1, 157-171.

Glynn, A. A. (1959). Antibodies to Haemophilus influenzae in chronic bronchitis. Brit. med. J., 2, 911-914.

Glynn, A. A., and Ward, M. E. (1970). Nature and heterogeneity of the antigens of Neisseria gonorrhoeae involved in the serum bactericidal reaction. Infect., Immun., 2, 162-168.

Lee, L., and Schmale, J. D. (1970). Identification of a gonococcal antigen important in the human immune response. Infect., Immun., 1, 207-208.

Maeland, J. A. (1968). Antigenic properties of various preparations of Neisseria gonorrhoeae endotoxin. Acta path. microbiol. scand., 73, 413-422.

Martin, J. E. Jr., Peacock, W. L. Jr., Reising, G., Kellogg, D. S. Jr., Ribi, E., and Thayer, J. D. (1969). Preparation of cell walls and protoplasm of Neisseria with the Ribi cell fractionator. J. Bact., 97, 1009-1011.

Price, I. N. O. (1930). The gonococcal complement fixation test: improvements in technique. J. Path. Bact., 33, 493-495.

Reising, G., and Kellogg, D. S. Jr. (1965). Detection of gonococcal antibody. Proc. Soc. exp. Biol. (N.Y.), 120, 660-663.

Reising, G., Schmale, J. D., Danielsson, D. G., and Thayer, J. D. (1969). Reactivity of two selected antigens of Neisseria gonorrhoeae. Appl. Microbiol., 18, 337-339.

Schmale, J. D., Danielsson, D. G., Smith, J. F., Lee, L., and Peacock, W. L. Jr. (1969). Isolation of an antigen of Neisseria gonorrhoeae, involved in the human immune response to gonococcal infection. J. Bact., 99, 469-471.

Ward, M. E., and Watt, P. J. (1971). The preservation of gonococci in liquid nitrogen. J. clin. Path., 24, 122-123. 